\title{
CORRESPONDENCE
}

Hypothermia in the elderly: scope for prevention

I Holtby, MRCGP, and R S Ramaiah, MFCM..... 551

Pregnancy and opiate addiction

Elizabeth Tylden, MRCPSYCH, and others ......

AIDS and medical confidentiality

$M$ Helbert, $M B$.

HIV infection: increase in public awareness

and anxiety

B A Evans, FRCP; C Sonnex, MRCP, and others; $M$ Veeravahu, MD, and others ........... others; $M$ Veeravah

N Rosedale, FRCPED
Infantile apnoea and home monitoring K P Dunne, MRCP, and T G Matthews, FRCPI; Ann Harvie, MRCP .

The myelodysplastic syndromes

A Jacobs, FRCP

Not all travellers need immunoglobulin for hepatitis A

Janet Palmer, FIMLS, and others...

Reduction in postprandial energy expenditure during pregnancy

P J Illingworth, $\mathrm{MB}$, and others

552 PJ Illingworth, $\mathrm{MB}$, and others.

552

\author{
Hypotensive and sedative effects of insulin in \\ autonomic failure \\ G Williams, MRCP, and J C Pickup, MRCPATH 555 \\ Hospital developments in Scotland

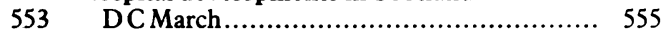 \\ The cost of nursing \\ D Jones; Lorraine K M Brooks ............... 555 \\ 554 Drug points Nephrotic syndrome associated \\ with diclofenac sodium (A M Yinnon and \\ others); Arrhythmias related to propofol \\ infusion ( $\mathrm{N}$ W Penfold and others); Tri- \\ infusion (N W Penfold and others); Tri- \\ Penmetcha) (............................... 556
}

All letters must be typed with double spacing and signed by all authors.

- No letter should be more than 400 words.

- For letters on scientific subjects we normally reserve our correspondence columns for those relating to issues discussed recently (within six weeks) in the BMF.

- We do not routinely acknowledge letters. Please send a stamped addressed envelope if you would like an acknowledgment.

- Because we receive many more letters than we can publish we may shorten those we do print, particularly when we receive several on the same subject.

\section{Hypothermia in the elderly: scope for prevention}

SIR,-With the increase in numbers of the very elderly (75 years and over) in the national population the report by Drs Catherine J Otty and M O Roland (15 August, $p$ 419) deserves consideration by all health districts. They suggest that hypothermia is a contributing factor in the deaths of many elderly people during the winter months and that those living alone with little or no support are most at risk. If elderly people would benefit from simple advice then this should be offered to all those who are at risk, in addition to further government support towards payment of heating bills.

Now, for the first time, using the databases of family practitioner committees, which contain information on all patients registered with general practitioners, we have the means to identify elderly people living alone. The use of such a database with no loss of confidentiality, could enable social services departments working with health

\section{Pregnancy and opiate addiction}

SIR,-We would like to add a few practical points to Dr Paul Caviston's leading article on pregnancy and opiate addiction (1 August, p 285).

The problem of infection with the human immunodeficiency virus (HIV) and infections generally cannot be dismissed by a reference to "dirty. needles and adulterants in street heroin." Eighty pregnant women addicted to opiates who were delivered at University College Hospital between 1975 and 1985 showed an increased incidence of antepartum haemorrhage, premature authority advice to prepare an information card for distribution to this group of people. Such a card might include a list of useful contact points, telephone numbers, and general advice to enable those susceptible to hypothermia to look after themselves. If this was done before the onset of cold weather it would alert those who need help to the problem of hypothermia and thus help prevent its occurrence.

The family practitioner committee database could also produce lists of those at risk for distribution to individual practices to enable health visitors, practice nurses, or general practitioners themselves to undertake educational follow up visits, which Drs Otty and Roland indicate would be beneficial.

I Hol.TBY

South Tees Health Authority, Middlesbrough, 'Cleveland TS7 0N

labour, and intrauterine death, which may occur during withdrawal. They also had 10 times as many serious infections as their matched controls; many infections were venereal and three were syphilitic. Venereal diseases are thought to predispose to the development of complications of HIV, and both syphilis and HIV are transmitted to the fetus. Early routine screening is not enough. Pregnancy causes anxiety, which increases the need for expensive drugs, and the easiest way to get the $£ 100$ to $£ 200$ a day needed for drugs is by prostitution, which, like dirty needles, spreads infection.

Drug addicts do not trust the medical and caring professions, so the most disturbed and ill addicts often present in labour pretending not to be addicted. These problems have worsened since the test case in which the baby of two addicts was taken into care at birth in Berkshire. The first appeal was allowed, but the case went to the House of Lords and the parents lost their child.

We do not know whether Dr Caviston agrees with this decision or not when he refers to breaking the vicious cycle of an irritable infant interacting with the vulnerable withdrawing mother in favour of "intensive educational support given in a structured parenting programme." We have not observed a vicious cycle of "infant passivity and maternal rejection"; in the many interactions we have seen addicted babies are often active, hungry, and crying. Their parents do not always handle them appropriately, but they do not necessarily reject them, seeing in their child the answer to their basic need to be loved, which they often believe led them to addiction. The programme Dr Caviston suggests does not as yet exist for any deprived children, least of all for those we consign to the theoretically comforting limbo of "care," away from the concern of their natural families and the often very appropriate help that might be provided by non-drug using relatives.

Pregnant addicts need careful antenatal care; the only way to ensure attendance in the first place is to provide small legal doses of opiates. Of course, any opiates put mother and baby at risk, but this is a lesser evil than continued use of black market drugs and offers an opportunity for a slow and safe reduction of the dose. From the baby's point of view heroin is preferable to methadone because the 
abstinence syndrome is less prolonged and severe.

The true goal is full abstinence and a normal baby, and most important to the future of the family is a trusting relationship between the mother and those caring for her.

\section{Elizabeth Tylden}

JUDITH DAWKINS Nigel Colley

Department of Academic Psychiatry,

University College and the Middlesex

Hospital Medical School,

London

\section{AIDS and medical confidentiality}

SIR,-The issue of confidentiality in the context of infection with human immunodeficiency virus (HIV) continues to cause controversy in both the medical and lay press. No one seems to have consulted those affected.

Drs Peter Fisk and Vincent Riley report in their letter (25 July, p 268) that a group of individuals in Leicester "were divided in their views about the confidentiality of information gained in [the] sexually transmitted disease clinic." They did not state to which group the individuals questioned belonged, although they presumably belonged to a group that was in some way perceived as being at high risk for infection with HIV.

In July I undertook a survey of 43 patients with the acquired immune deficiency syndrome (AIDS) attending the Praed Street Clinic at this hospital Most (32 patients; 74\%) were registered with general practitioners, and 25 of these felt that they would rather contact the hospital than their genera practitioner if a problem arose, whether it was perceived as being related to HIV infection or not The reasons given were as follows: confidentiality $(50 \%)$, lack of experience on the part of the genera practitioner $(28 \%)$, better cover from sexually transmitted diseases clinic in general (14\%), and no particular reason $(9 \%)$

These results suggest that confidentiality is a major factor in preventing people with AIDS from continuing their relationship with their general practitioner. At a time when the Department of Health and Social Security is trying to develop community resources for people with AIDS and is setting up ways of educating primary care physicians in the management of problems related to HIV infection, it seems sad that the issue of confidentiality remains such a source of doubt for these patients. This survey was conducted in late July, after the BMA conference; one wonders what the impact of the conference was on the results and how we can redeem ourselves as a profession.

MATTHEW HeLBERT

Jefferiss Research Wing,

St Mary's Hospital,

London W2 INY

\section{HIV infection: increase in public awareness} and anxiety

SIR,_Dr C Sonnex and colleagues (18 July, p 193) present a unique approach to preventive medicine. They set out with the premise that "Those who work with HIV infection have always seen it as being sexually transmitted and thus have been fully aware of the potential heterosexual spread."

During the three month study period 847 patients attended for testing, but roughly a quarter (206) "decided against the test after counselling." More than half of these patients (106) were heterosexual and concerned about previous bisexual partners, prostitutes, or casual girlfriends. The counsellors somehow managed to allay such anxiety sufficiently to persuade the patients to leave untested. But did they allay their patients' anxieties? I suggest that their worries would have been more expeditiously and thoroughly alleviated by testing, that the counsellors had neither the right nor the knowledge to dissuade them from the purpose of their visit, and that to pursue this approach is inconsistent with the public interest of establishing the transmission risks of the human immunodeficiency virus (HIV).

Having found two heterosexual men to be positive (and no women), the authors conclude that "This is somewhat concerning and emphasises the potential spread into the heterosexual community." One of these men had been misbehaving in Zimbabwe and the other used intravenous drugs. Surely I am not alone in the conviction that this is not science or the proper practice of preventive medicine? West London Hospital,
London W6 7DQ

B A Evans

AUTHORS' REPLY, - We thank Dr Evans for raising an important issue regarding our paper and for providing us with an opportunity to clarify a few points. It is correct that 106 out of 206 attenders who decided against testing for antibodies to HIV after counselling were heterosexual. The table shows, however, that not all of these were concerned about previous bisexual partners, prostitutes, or casual girlfriends; these accounted for only $28 \cdot 5 \%, 17 \cdot 7 \%$, and $18 \cdot 2 \%$ of requests, respectively. We agree with Dr Evans that these patients are unlikely to have their anxieties allayed by counselling, and indeed most of the second and third groups were tested.

With regard to bisexual contact, it was interesting that on further questioning many women began to doubt whether past boyfriends had in fact been bisexual. After discussion, not dissuasion, many of this group decided against testing. In addition, some people were not tested when they attended if their risk contact had been recent because of the delay between infection with HIV and the development of antibodies. We apologise for not making this point clear. An important statement not quoted by Dr Evans was that most heterosexuals not tested "were at minimal risk of exposure and showed disproportionate anxiety about AIDS owing to lack of knowledge about HIV infection." These were alluded to in the "miscellaneous" category at the foot of the table and comprised those who had social contact with high risk groups, those who had suffered insect bites while travelling abroad, etc. We are confident that our counsellors have the "knowledge to dissuade" this group "from the purpose of their visit," but dissuasion is rarely used. It has always been the policy of this clinic to test anyone wishing to know their HIV antibody state. Our counsellors provide information from which the individual concerned can make a decision whether to be tested.

PETHERICK

$M$ W ADLER

J D MILLER

Middlesex Hospital Medical School, London W1N 8AA

SIR,-Dr C Sonnex and coworkers (18 July, p 193) show that the publicity campaigns about the acquired immune deficiency syndrome (AIDS) were successful in motivating men and women to attend for screening. We report on another desirable aspect of the recent media events concerned with AIDS

We reviewed the case records of new and existing patients who attended our clinic during
March 1987 (during and soon after the week of media coverage on AIDS). A total of 1193 patients (692 men and 501 women) were seen, $70 \%$ of whom were new patients. Though this amounted to a $34 \%$ increase in attendance over March 1986 , only a modest increase $(9 \%)$ was evident over February 1987, and a fall of $17 \%$ occurred in April 1987 , after the media campaign.

The human immunodeficiency virus (HIV) antibody test was requested by 173 men (25\%) and 101 women (20\%). Of the 102 men and 61 women who decided to have the test, only three men (all homosexual) were positive. All of the patients who requested the test were offered counselling and screening for other sexually transmitted diseases.

A reason for seeking the test was given by 79 men (30 homosexual, 10 bisexual, 17 several heterosexual partners, 12 intercourse with prostitutes, three drug abusers, and seven miscellaneous reasons) and 57 women ( 16 consort bisexual, 16 sex with several partners, nine consort promiscuous, three consort drug abuser, three history of blood transfusions, and 10 miscellaneous reasons).

Though three men $(1 \cdot 7 \%)$ and 27 women (27\%) declined screening for sexually transmitted diseases, a new condition was diagnosed in 23 men $(13 \%)$ and 24 women $(24 \%)$. Of the six cytological abnormalities detected, one was reported as "positive, severe dyskaryosis with warty atypia." Colposcopy and biopsy confirmed the diagnosis of cervical intraepithelial neoplasia stage III, which was treated by laser vaporisation. This patient had had intercourse with a drug abuser nine months previously and had attended purely to have a test for HIV. The table summarises the results.

Number (percentage) of new conditions diagnosed in those presenting for HIV tests during March 1987

\begin{tabular}{|c|c|c|}
\hline Diagnosis & $\begin{array}{c}\text { Men } \\
(n=173)\end{array}$ & $\begin{array}{l}\text { Women } \\
(n=101)\end{array}$ \\
\hline Total No of new conditions & $23(13)$ & $24(24)$ \\
\hline Chlamydial infection & $3(1 \cdot 7)$ & $6(6)$ \\
\hline Non-gonococcal urethritis* & $6(4)$ & - \\
\hline Trichomonal infection & - & $1(1)$ \\
\hline Warts & $8(5)$ & $1(1)$ \\
\hline Gonorrhoea & $1(1)$ & 0 \\
\hline Tinea cruris/bacterial vaginosis & $2(1)$ & $4(4)$ \\
\hline Abnormal cervical cytology & - & $6(6)$ \\
\hline Balanitis/candidiasis & $3(2)$ & $6(6)$ \\
\hline Hepatitis B markers & $14(8)$ & $2(2)$ \\
\hline Syphilis markers & $9(5)$ & \\
\hline
\end{tabular}

Other than those with positive cultures for Chlamydia trachomatis.

Some of the patients requesting the test would probably have attended even in the absence of a publicity campaign. Nevertheless, we are confident that the campaign helped in uncovering new conditions that would otherwise have been missed. Thus in spite of the increase in workload we believe that whenever possible all those who present for tests for HIV (whether high risk or not) should be persuaded to have screening tests for other sexually transmitted diseases.

M VeERaVahu A R G MANUEL J C Clay

Department of Genitourinary Medicine, General Hospital,

Birmingham B4 6NH

\section{AIDS and insurance}

SIR,-Problems encountered in obtaining life insurance as discussed in Medical News (22 August, p 507) are a favourite topic of those who counsel patients with the acquired immune 